\title{
HEALTH RISK TO MEDICAL PERSONNEL OF SURGICAL SMOKE PRODUCED DURING LAPAROSCOPIC SURGERY
}

\author{
MIŁOSZ DOBROGOWSKI ${ }^{1}$, WIKTOR WESOŁOWSKI ${ }^{2}$, MAŁGORZATA KUCHARSKA ${ }^{2}$, \\ KATARZYNA PADUSZYŃSKA ${ }^{1}$, AGNIESZKA DWORZYŃSKA ${ }^{1}$, WIESŁAW SZYMCZAK ${ }^{3}$, \\ ANDRZEJ SAPOTA ${ }^{4}$, and LECH POMORSKI ${ }^{1}$
}

${ }^{1}$ Medical University of Lodz, Łódź, Poland

Department of General and Oncological Surgery

${ }^{2}$ Nofer Institute of Occupational Medicine, Łódź, Poland

Department of Chemical Hazard

${ }^{3}$ University of Lodz, Łódź, Poland

Institute of Psychology

${ }^{4}$ Medical University of Lodz, Łódź, Poland

Department of Toxicology and Bromatology

\begin{abstract}
Objectives: During laparoscopic cholecystectomy, the removal of the gall bladder, pyrolysis occurs in the peritoneal cavity. Chemical substances which are formed during this process escape into the operating room through trocars in the form of surgical smoke. The aim of this study was to identify and quantitatively measure a number of selected chemical substances found in surgical smoke and to assess the risk they carry to medical personnel. Material and Methods: The study was performed at the Maria Skłodowska-Curie Memorial Provincial Specialist Hospital in Zgierz between 2011 and 2013. Air samples were collected in the operating room during laparoscopic cholecystectomy. Results: A complete qualitative and quantitative analysis of the air samples showed a number of chemical substances present, such as aldehydes, benzene, toluene, ethylbenzene, xylene, ozone, dioxins and others. Conclusions: The concentrations of these substances were much lower than the hygienic standards allowed by the European Union Maximum Acceptable Concentration (MAC). The calculated risk of developing cancer as a result of exposure to surgical smoke during laparoscopic cholecystectomy is negligible. Yet it should be kept in mind that repeated exposure to a cocktail of these substances increases the possibility of developing adverse effects. Many of these compounds are toxic, and may possibly be carcinogenic, mutagenic or genotoxic. Therefore, it is necessary to remove surgical smoke from the operating room in order to protect medical personnel.
\end{abstract}

Key words:

Smoke, Exposure, Volatile organic compounds, Dioxins, Health risk, Laparoscopic cholecystectomy, Pyrolysis

The study was supported by the grant No. 1767/B/P01/2010/39 from the National Science Centre, Poland. Manager of grant: Lech Sylwester Pomorski, Prof. Received: July 2, 2014. Accepted: December 18, 2014.

Corresponding author: M. Dobrogowski, Medical University of Lodz, Department of General and Oncological Surgery, Parzęczewska 35, 95-100 Zgierz, Poland (e-mail: miloszd@onet.pl). 


\section{INTRODUCTION}

Coagulation is used during surgery to cut and separate tissues and to ligate vessels. Since the peritoneal cavity is inflated with carbon dioxide, surgical smoke, an unwanted by product of coagulation, is formed in an oxygen-free atmosphere [1].

As a result of pyrolysis a number of chemical substances, which are known to have a toxic effect on the human body, are formed. Some identified substances of surgical smoke include aromatic hydrocarbons, unsaturated hydrocarbons, aldehydes, alcohols and ketones, as well as dioxins. Many of these substances are recognized to be mutagenic, teratogenic and carcinogenic $[2,3]$. The presence of these substances in the urine of the operated patients proves that they are absorbed by the peritoneum into the organism. Although laparoscopic surgical procedures are performed in the peritoneal cavity, which is a limited, enclosed space, the manipulation of laparoscopic tools causes surgical smoke to leak through trocars from the peritoneal cavity into the operating room. Medical personnel are exposed to the chemical substances which it contains on an average of $7 \mathrm{~h}$ per day, 5 days a week over a period of many years. Most of these compounds are absorbed easily into the respiratory tract and by the skin. The symptoms of exposure are: irritation and inflammation of the airways, coughing, headaches, dizziness, nausea and vomiting, irritation and conjunctivitis [4,5].

The aim of this study was to identify and quantitatively assess the presence of a group of selected chemical substances in the atmosphere of the operating room during laparoscopic cholecystectomy, and to assess the health risk they carry to medical personnel.

\section{MATERIAL AND METHODS}

\section{Air sample collection}

Air samples were collected and analysed for aldehydes, ozone, volatile organic compounds, and PCDD/PCDF in 3 steps (Figure 1).

\section{Location of sampling points}

The air samples were collected at the surgical ward of the Maria Skłodowska-Curie Memorial Provincial Specialist Hospital in Zgierz.

The surgical ward consists of 4 operating rooms which, together with the preparatory rooms, make up an enclosed area. Control air samples were collected outside this described area from a changing room. The sampling was performed in a $28 \mathrm{~m}^{2}$ operating room during laparoscopic surgeries. The operating room is equipped with a natural ventilation system (without forced air flow).

\section{Air sampling protocol}

Air sampling was performed by a stationary test method within the breathing zone of medical personnel located near the operating table. Due to the characteristics of work, all measuring probes were located within $1.5 \mathrm{~m}$ from the monitored personnel. Samples were collected only during laparoscopic procedures.

Depending on the substances measured, air samples were collected using appropriate filters and absorbents.

\section{Aldehydes and ozone}

Air samples were collected using EHA-Air-350 individual aspirators onto LpDNPH Rezorian ${ }^{\mathrm{TM}}$ cartridge tubes (Supelco 54279-U). These tubes are filled with 2 layers of silica gel. One is covered with trans-1,2-bis-(4-pyridyl)ethylene (BPE) and is used for the determination of ozone. The other is covered with 2,4-dinitrophenylhydrazine (DNPH) which allows the determination of carbonyl compounds (aldehydes). Between 60 and $330 \mathrm{dm}^{3}$ of air was analyzed.

\section{Volatile organic compounds}

EHA-Air-350 individual aspirators were used to collect air samples. The samples were passed through $\mathrm{ORBO}^{\mathrm{TM}} 32$ activated coconut shell charcoal sorbent tubes. Between 10 and $50 \mathrm{dm}^{3}$ of air was tested. 


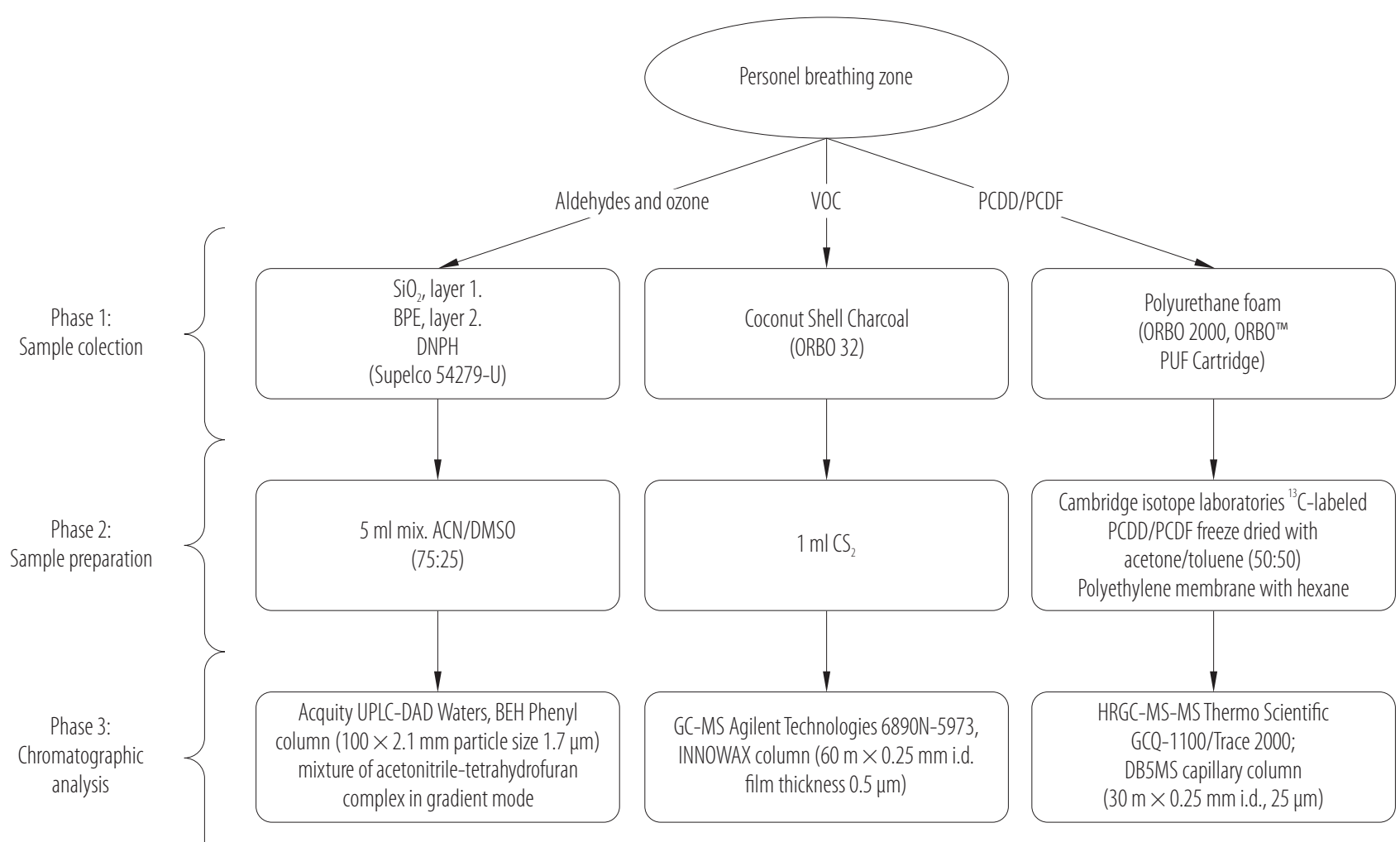

VOC - volatile organic compounds; PCDD/PCDF - polychlorinated dibenzo-p-dioxins and polychlorinated dibenzofurans; $\mathrm{Sio}_{2}$ - silicon dioxide; BPE - trans-1,2-bis-(4-pyridyl)ethylene; DNPH- 2,4-dinitrophenylhydrazine; PUF - polyurethane foam; ACN-DMSO - acetonitrile and dimethyl sulfoxide mixture; $\mathrm{CS}_{2}$ - carbon disulfate; UPLC-DAD - ultra performance liquid chromatography with diode array detection; GC-MS - gas chromatography - mass spectrometry; HRGC - high resolution gas chromatography.

Fig. 1. Steps of sampling and analysis of air from the operating room

\section{PCDD/PCDF (polychlorinated dibenzo-p-dioxins} and polychlorinated dibenzofurans)

Air samples were collected using a high flow aspirator measurement set filled with polyurethane foam (ORBO 2000, ORBO ${ }^{\mathrm{TM}}$ PUF Cartridge). From 3 to $13 \mathrm{~m}^{3}$ of air was analyzed.

\section{Identifying the main compounds of the air samples}

Gas chromatography - mass spectrometry (GC-MS Agilent Technologies 6890N-5973) was used to identify the compounds in the air samples. The mass spectra recorded from the samples were compared with reference chromatographic peak mass spectrum appearing in the WILEY7 registry of mass spectral, which contains
275000 records, and with retention times of appropriate peaks with standard sample peaks.

Determining the concentrations of aldehydes, ozone, volatile organic compounds (VOC), and PCDD/PCDF in the air of the operating room during laparoscopic procedures

Principles of determination

Aldehydes and ozone

The method of determinations is based on a reaction between carbonyl compounds and 2,4-dinitrophenylhydrazine (DNPH). Stable, colored derivatives of dinitrophenylhydrazones are formed during this reaction. Ozone found in the analyzed air reacts with trans-1,2-bis-(4-pyridyl)ethyl 
ene (BPE) and forms pyridine-2-aldehyde (2-PA). In the process during which dinitrophenylhydrazone is washed out of tubes, 2-PA reacts with DNPH and forms respective dinitrophebylhydrazones.

\section{Volatile organic compounds}

The principles of the method are based on the absorption of vapors of studied compounds on carbon, followed by chromatographic analysis of the eluted carbon disulphide.

\section{PCDD/PCDF}

The studied substances were retained on a filter made of a special foam prepared of polyurethane designed to analyze persistent organic pollutants (POP's). The collected samples were prepared for chromatographic analysis using mass detection compatible with the determination procedure using isotope dilution mass spectrometry (IDMS).

\section{Sample handling}

\section{Aldehydes and ozone}

Compounds formed during the reaction between DNPH and $\mathrm{BPH}$ were washed out of the absorbing tubes with $5 \mathrm{ml}$ of acetonitrile and dimethyl sulfoxide mixture (DMSO) (75:25). The resultant solution was then analyzed using ultra performance liquid chromatography (UPLC) and detection using $360 \mathrm{~nm}$ wavelength spectrophotometry.

\section{Volatile organic substances}

The carbon from the tubes was transferred into measuring containers and eluted with $1 \mathrm{ml}$ of carbon disulphide. The resultant eluate was subjected to chromatographic analysis with mass detection.

\section{PCDD/PCDF}

Each sample of PP tubing was cut into small particles less than $1 \mathrm{~cm}$ long and combined with exposed PU foam plugs, spiked with ${ }^{13} \mathrm{C}$-labeled PCDD/PCDF standards
(Cambridge Isotope Laboratories), freeze dried and extracted overnight in a Soxhlet extractor with acetone/toluene (50:50). The extract was dried with anhydrous sodium sulphate using a rotary evaporator to obtain ca. $20 \mathrm{ml}$ samples.

The concentrated extract was placed in the bottom-sealed polyethylene semipermeable membrane tube of $80 \mu \mathrm{m}$ wall thickness and cleaned up with $100 \mathrm{ml}$ hexane overnight. The hexane dialysate was cleaned up on a silica gel coated with $44 \%$ sulphuric acid placed in LC column. Polychlorinated dibenzo-p-dioxins and polychlorinated dibenzofurans (PCDD/PCDF) were fractionated on basic alumina. The final extract was spiked with $20 \mu \mathrm{l}$ of ${ }^{13} \mathrm{C}$ labeled 1,2,3,4-TCDD (tetrachlorobenzo-p-dioxin) precision and recovery solution prepared in nonane and evaporated to ca. $20 \mu \mathrm{l}$ in a gentle stream of nitrogen.

\section{Measuring instruments and parameters \\ Aldehydes and ozone}

Determinations were performed using an Acquity UPLC liquid chromatograph manufactured by Waters, equipped with a spectrophotometric detector operated at $360 \mathrm{~nm}$, and a BEH phenyl column $(100 \times 2.1 \mathrm{~mm})$, particle size $1.7 \mu \mathrm{m}$. The compounds to be determined were eluted from the column in gradient mode using the acetonitriletetrahydrofuran mixture.

\section{Volatile organic compounds}

Determinations of volatile organic compounds were performed by gas chromatography using an Agilent Technologies $6890 \mathrm{~N}$ apparatus equipped with a mass detector 5973, a split/splitless injector chamber, an Innowax capillary column (length: $60 \mathrm{~m}$, diameter: $0.25 \mathrm{~mm}$, film thickness of the stationary phase: $0.5 \mu \mathrm{m}$ ) and a computer data acquisition station. The analyses were performed at programmable oven temperatures of the columns $\left(40^{\circ} \mathrm{C}(2 \mathrm{~min}), 5^{\circ} \mathrm{C} / \mathrm{min}\right.$ $\left.\rightarrow 80^{\circ} \mathrm{C}(0 \mathrm{~min}), 20^{\circ} \mathrm{C} / \mathrm{min} \rightarrow 180^{\circ} \mathrm{C}(15 \mathrm{~min})\right)$, and temperature of the split/splitless injection chamber of $200^{\circ} \mathrm{C}$. 
Scanning was performed, at the same time as data acquisition in the selective ion monitoring (SIM) mode. The scanning range was $10 \mathrm{Da}$ to $250 \mathrm{Da}$. The signal for the SIM was collected for specific masses of aromatic hydrocarbons:

- group 1 (benzene) - 50.0, 51.0, 52.0, 78.0 Da;

- group 2 (toluene) - 65.0, 91.0, 92.0 Da;

- group 3 (ethylbenzene, xylene) - 51.0, 65.0, 91.0, 105.0, 106.0 Da;

- group 4 (naphthalene, biphenyl, alkyl derivatives of benzene C9-C10) - 105.0, 120.0, 128.0, 134.0, 154.0 Da.

\section{PCDD/PCDF}

Determination of PCDD/PCDF was performed by isotope dilution high resolution chromatography/tandem mass spectrometry (ID-HRGC/MS-MS) on a Thermo Scientific GCQ-1100/Trace2000 system equipped with Xcalibur data acquisition and analysis software. Separation was performed on a $30 \mathrm{~m} \times 0.25 \mathrm{~mm}$ i.d. DB5MS J\&W capillary column of $25 \mu \mathrm{m}$ film and DB17 $30 \mathrm{~m} \times 0.25 \mathrm{~mm}$ i.d. DB5MS J\&W capillary column of $25 \mu \mathrm{m}$ film. Samples of $2.5 \mu \mathrm{l}$ were injected into a SSL injector at $260^{\circ} \mathrm{C}$. Temperatures of the $\mathrm{GC}$ oven were programmed as follows: an initial temperature of $130^{\circ} \mathrm{C}$ was held for $3 \mathrm{~min}$, then the temperature was ramped $50^{\circ} \mathrm{C}$ per min to $180^{\circ} \mathrm{C}$, next the temperature was raised at $2^{\circ} \mathrm{C}$ per min to $270^{\circ} \mathrm{C}$.
Finally, the temperature was increased at $20^{\circ} \mathrm{C}$ per min to $300^{\circ} \mathrm{C}$ and held for $5 \mathrm{~min}$.

\section{RESULTS}

\section{Aldehydes and ozone}

Identification of aldehydes in air samples was done by comparing the retention times of peaks to corresponding peak patterns. On the basis of that identification we found formaldehyde, acetic acid, pyridine-2-aldehyde, ozone, acetone, propionaldehyde, methacrolein, butyraldehyde and benzaldehyde (samples MA-R-5 to MA-R-10). Samples R-MA-11 to MA-20-R (with the exception of sample MA-R-15), contained valeric aldehyde and hexyl.

Table 1 shows the results of quantitative measurements of selected aldehydes and ozone in air samples collected in the operating room. The concentrations of all identified compounds were significantly lower (10-fold or more) than corresponding MAC values currently valid in Poland. The concentrations of formaldehyde and acetaldehyde were the highest.

Table 2 shows the results of the quantitative measurement of selected volatile organic compounds in the analyzed samples of air. The concentrations of all identified compounds were also well below the OEL.

Table 3 shows the results of measurements, for example, concentrations of dioxins and furans, and their isomers

Table 1. Concentration of aldehydes and ozone in the air in the operating room during laparoscopic surgery

\begin{tabular}{|c|c|c|c|c|c|c|c|c|c|}
\hline \multirow{2}{*}{$\begin{array}{l}\text { Statistical } \\
\text { parameters }\end{array}$} & \multicolumn{9}{|c|}{$\begin{array}{l}\text { Tested substance concentration } \\
\qquad\left[\mathrm{mg} / \mathrm{m}^{3}\right]\end{array}$} \\
\hline & $\begin{array}{l}\text { formal- } \\
\text { dehyde }\end{array}$ & ozone & $\begin{array}{l}\text { metha- } \\
\text { crolein }\end{array}$ & $\begin{array}{l}\text { acetal- } \\
\text { dehyde }\end{array}$ & $\begin{array}{c}\text { propional- } \\
\text { dehyde }\end{array}$ & $\begin{array}{l}\text { butyral- } \\
\text { dehyde }\end{array}$ & $\begin{array}{l}\text { benzal- } \\
\text { dehyde }\end{array}$ & $\begin{array}{l}\text { valeral- } \\
\text { dehyde }\end{array}$ & $\begin{array}{l}\text { hexyl } \\
\text { aldehyde }\end{array}$ \\
\hline Mean & 0.0184 & 0.0138 & 0.0009 & 0.0120 & 0.0015 & 0.0010 & 0.0010 & 0.0006 & 0.0006 \\
\hline SE & 0.0023 & 0.0031 & 0.0006 & 0.0017 & 0.0003 & 0.0000 & 0.0000 & 0.0001 & 0.0001 \\
\hline Min. & 0.0075 & 0.0000 & 0.0000 & 0.0010 & 0.0010 & 0.0010 & 0.0010 & 0.0001 & 0.0001 \\
\hline Max & 0.0495 & 0.0434 & 0.0010 & 0.0321 & 0.0052 & 0.0010 & 0.0010 & 0.0010 & 0.0010 \\
\hline MAC & 0.5000 & 0.1500 & $\begin{array}{c}\text { not } \\
\text { specified }\end{array}$ & 45.0000 & $\begin{array}{c}\text { not } \\
\text { specified }\end{array}$ & $\begin{array}{c}\text { not } \\
\text { specified }\end{array}$ & 10.0000 & $\begin{array}{c}\text { not } \\
\text { specified }\end{array}$ & $\begin{array}{c}\text { not } \\
\text { specified }\end{array}$ \\
\hline
\end{tabular}

SE - standard error; min. - minimal value; max - maximal value; MAC - maximum acceptable concentration. 
Table 2. Results of measurements of the concentration of organic solvents in the air in the operating room during laparoscopic surgery

\begin{tabular}{lccccccc}
\hline \multirow{2}{*}{$\begin{array}{c}\text { Statistical } \\
\text { parameters }\end{array}$} & \multicolumn{7}{c}{$\begin{array}{c}\text { Tested substance concentration } \\
{\left[\mathrm{mg} / \mathrm{m}^{3}\right]}\end{array}$} \\
\cline { 2 - 8 } & benzene & toluene & ethylbenzene & $p$-xylene & $m$-xylene & $o$-xylene & acetone \\
\hline Mean & 0.0049 & 0.308 & 0.0044 & 0.0050 & 0.0092 & 0.0030 & 0.1028 \\
SE & 0.0013 & 0.020 & 0.0020 & 0.0022 & 0.0048 & 0.0011 & 0.0170 \\
Min. & 0.0006 & 0.108 & 0.0001 & 0.0002 & 0.0002 & 0.0001 & 0.0310 \\
Max & 0.0190 & 0.498 & 0.0400 & 0.0454 & 0.0973 & 0.0225 & 0.2718 \\
MAC & 1.6000 & 100.000 & 200.0000 & - & 100.0000 & - & 600.0000 \\
& & & & & for all isomers & \\
\hline
\end{tabular}

Abbreviations as in Table 1.

Table 3. International toxic equivalent (I-TEQ) levels of dioxins and furans in 2 exemplary samples (MP11, MP12) and the method of calculating the equivalent value for the mixture

\begin{tabular}{|c|c|c|c|c|c|c|c|}
\hline \multirow{2}{*}{ Dioxins and furans } & \multirow{2}{*}{$\begin{array}{c}\text { NATO } \\
\text { TEF }\end{array}$} & \multicolumn{3}{|c|}{$\begin{array}{c}\text { MP11 } \\
\text { (volume of air collected: } 12.5 \mathrm{~m}^{3} \text { ) }\end{array}$} & \multicolumn{3}{|c|}{$\begin{array}{c}\text { MP12 } \\
\text { (volume of air collected: } 9.8 \mathrm{~m}^{3} \text { ) }\end{array}$} \\
\hline & & $\begin{array}{l}\text { amount collected } \\
\text { [pg/sample] }\end{array}$ & $\begin{array}{c}\text { concentration } \\
{\left[\mathrm{pg} / \mathrm{m}^{3}\right]}\end{array}$ & $\begin{array}{l}\text { concentration } \\
\quad \times \text { TEF }\end{array}$ & $\begin{array}{c}\text { amount collected } \\
\text { [pg/sample] }\end{array}$ & $\begin{array}{l}\text { concentration } \\
{\left[\mathrm{pg} / \mathrm{m}^{3}\right]}\end{array}$ & $\begin{array}{l}\text { concentration } \\
\quad \times \text { TEF }\end{array}$ \\
\hline 2,3,7,8-TCDD & 1.000 & 0.25 & 0.020 & 0.02000 & 0.25 & 0.0255 & 0.0255 \\
\hline 1,2,3,7,8-PCDD & 0.500 & 0.25 & 0.200 & 0.01000 & 0.25 & 0.0255 & 0.0128 \\
\hline 1,2,3,4,7,8-HxCDD & 0.100 & 0.20 & 0.016 & 0.00160 & 0.15 & 0.0153 & 0.0015 \\
\hline 1,2,3,6,7,8-HxCDD & 0.100 & 0.10 & 0.008 & 0.00080 & 0.10 & 0.0102 & 0.0010 \\
\hline 1,2,3,7,8,9-HxCDD & 0.100 & 0.15 & 0.012 & 0.00120 & 0.15 & 0.0153 & 0.0015 \\
\hline 1,2,3,4,6,7,8-HpCDD & 0.010 & 0.15 & 0.012 & 0.00012 & 0.60 & 0.0612 & 0.0006 \\
\hline OCDD & 0.001 & 2.80 & 0.224 & 0.00022 & 5.30 & 0.5408 & 0.0005 \\
\hline 2,3,7,8-TCDF & 0.100 & 4.45 & 0.356 & 0.03560 & 4.20 & 0.4286 & 0.0429 \\
\hline 1,2,3,7,8-PCDF & 0.050 & 0.30 & 0.024 & 0.00120 & 0.45 & 0.0459 & 0.0023 \\
\hline 2,3,4,7,8-PCDF & 0.500 & 0.60 & 0.048 & 0.02400 & 0.65 & 0.0663 & 0.0332 \\
\hline 1,2,3,4,7,8-HxCDF & 0.100 & 0.60 & 0.048 & 0.00480 & 0.95 & 0.0969 & 0.0097 \\
\hline 1,2,3,6,7,8-HxCDF & 0.100 & 0.60 & 0.048 & 0.00480 & 0.90 & 0.0918 & 0.0092 \\
\hline 1,2,3,7,8,9-HxCDF & 0.100 & 0.75 & 0.060 & 0.00600 & 0.70 & 0.0714 & 0.0071 \\
\hline 2,3,4,6,7,8-HxCDF & 0.100 & 0.70 & 0.056 & 0.00560 & 0.65 & 0.0663 & 0.0066 \\
\hline 1,2,3,4,6,7,8-HpCDF & 0.010 & 1.50 & 0.120 & 0.00120 & 1.45 & 0.1480 & 0.0015 \\
\hline 1,2,3,4,7,8,9-HpCDF & 0.010 & 0.85 & 0.068 & 0.00068 & 1.00 & 0.1020 & 0.0010 \\
\hline OCDF & 0.001 & 0.40 & 0.032 & 0.00003 & 0.55 & 0.0561 & 0.0001 \\
\hline $\begin{array}{l}\text { Sum of concentrations } \\
\quad \times \text { TEF, I-TEQ }\left[\mathrm{pg} / \mathrm{m}^{3}\right]\end{array}$ & - & - & - & 0.11800 & - & - & 0.1570 \\
\hline
\end{tabular}

TCDD - tetrachlorodibenzodioxin; PCDD - polychlorinated dibenzodioxins; HxCDD - hexachlorodibenzo-p-dioxin; HpCDD - heptachlorodibenzop-dioxin; OCDD - octachlorodibenzodioxin; TCDF - tetrachlorodibenzofuran; PCDF - polychlorinated dibenzofurans; HxCDF - hexachlorodibenzofuran; HpCDF - heptachlorodibenzofuran; OCDF - octachlorodibenzofuran.

NATO - North Atlantic Treaty Organization; TEF - toxicity equivalence factor. 
Table 4. Validation method for the determination of solvents (benzene, toluene, ethylbenzene, $o-, m-, p$-xylene)

\begin{tabular}{|c|c|c|c|c|c|c|}
\hline Validation method & Benzene & Toluene & Ethylbenzene & $p$-Xylene & $m$-Xylene & $o$-Xylene \\
\hline Regression equation & $\begin{array}{c}y=663.99 x- \\
64354\end{array}$ & $\begin{array}{c}y=1083.3 x- \\
95667\end{array}$ & $\begin{aligned} y= & 1087.8 x+ \\
& 2631.4\end{aligned}$ & $\begin{aligned} y= & 1073.8 x+ \\
& 879.91\end{aligned}$ & $\begin{array}{c}y=1022 x+ \\
1570.9\end{array}$ & $\begin{array}{c}y=1067.2 x+ \\
2183.7\end{array}$ \\
\hline Correlation coefficient (R) & 0.9997 & 0.9999 & 0.9998 & 0.9999 & 0.9999 & 0.9999 \\
\hline $\begin{array}{l}\text { Working range of } \\
\text { the method }[\mu \mathrm{g} / \mathrm{ml}]\end{array}$ & $0.10-50.00$ & $0.50-50.00$ & $0.01-0.50$ & $0.01-1.00$ & $0.01-1.00$ & $0.01-0.50$ \\
\hline $\begin{array}{l}\text { Limit of detection (LOD) } \\
{[\mu \mathrm{g} / \mathrm{ml}]}\end{array}$ & 0.022 & 0.034 & 0.002 & 0.001 & 0.002 & 0.002 \\
\hline $\begin{array}{l}\text { Limit of quantification } \\
\text { (LOQ) }[\mu \mathrm{g} / \mathrm{ml}]\end{array}$ & 0.075 & 0.112 & 0.007 & 0.004 & 0.005 & 0.006 \\
\hline Uncertainty of analysis [\%] & 7.40 & 4.00 & 12.60 & 6.00 & 7.70 & 8.70 \\
\hline
\end{tabular}

in 2 samples (MP11 and MP12). Table 4 presents validation method for the determination of solvents (benzene, toluene, ethylbenzene, $o-, m-, p$-xylene).

The concentrations of dioxins and furans were as low as the detection limit of the method. International toxic equivalent (I-TEQ) values were used to compare the toxicity of each PCDD/PCDF mixture. To calculate the total PCDD/PCDF toxic equivalent (I-TEQ) of a dioxin mixture, the amounts of each toxic compound are multiplied with their Toxic Equivalency Factor (TEF) and then added together.

Figure 2 shows the value of I-TEQ $\left(\mathrm{pg} / \mathrm{m}^{3}\right)$ in the individual air samples. The average value of the concentration is about $0.2 \mathrm{pg} / \mathrm{m}^{3}$. These values are very low. For

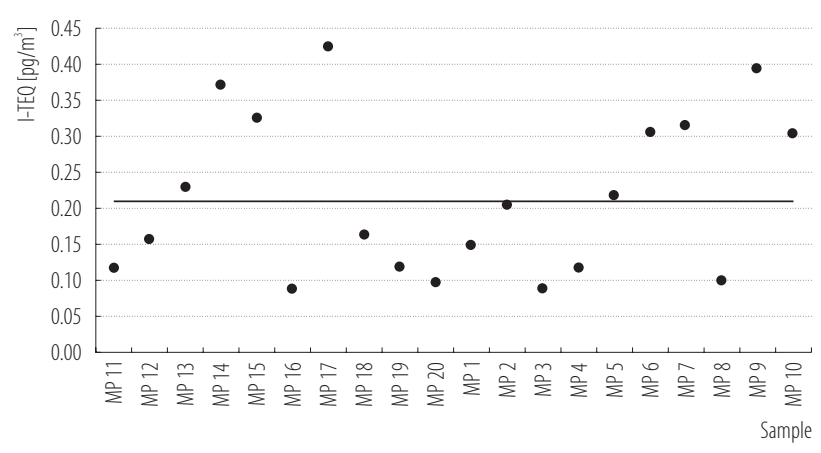

I-TEQ - international toxic equivalent.

The line represents the mean value from all samples I-TEQ.

Fig. 2. I-TEQ (equivalent value for the mixture) values in each sample comparison, Germany assumed a value of $50 \mathrm{pg} / \mathrm{m}^{3}$ as the hygienic standard (MAK) value.

\section{DISCUSSION}

Surgical smoke may pose a potential threat, to patients as well as the medical personnel working in the operating room, due to the chemical substances that it contains.

Around 600 different chemical substances, including dioxins, are found in surgical smoke usually in very low, trace concentrations. These substances have been proved to be mutagenic, carcinogenic and teratogenic. Their synergetic and antagonistic interactions have not yet been studied and are difficult to predict.

In our study we chose to assess the risk to medical personnel of only those chemical substances that showed relatively high concentrations in the air of the operating room. A quantitative analysis of air samples found very low, trace, concentrations of the chosen substances, several times lower than the respective hygienic standard values. However, as medical personnel is repeatedly exposed to this multicomponent mixture of substances of very diverse toxicity, even at very low concentrations of individual components, the risk to the health of the exposed persons may be significant. Therefore, we attempted to assess the health risk from our results. 


\section{Assessment of the risk of developing cancer \\ as a result of exposure to surgical smoke \\ during laparoscopic operations}

The concentrations of the following substances were measured in the operating room during laparoscopic surgery: benzene, toluene, ethylbenzene, $p$-xylene, $o$-xylene as well as dioxins and furans: 2,3,7,8-TCDD, 1,2,3,4,7,8-HxCDD, 1,2,3,4,6,7,8-HpCDD, OCDD, 2,3,7,8-TCDF, 1,2,3,6,7,8HxCDF, OCDF.

Out of all the identified aromatic carbohydrates, only benzene is classified as a carcinogen in humans. Exposure to benzene may result in leukemia.

For benzene "a range of the slope of the linear dose-response relationship $2.2 \times 10^{-6} \div 7.8 \times 10^{-6}(0.0000022 \div 0.0000078)$ is the increase in the lifetime risk of an individual who is exposed for a lifetime to $1 \mu \mathrm{g} / \mathrm{m}^{3}$ benzene in air" [6].

In the operating room, we observed concentrations of benzene ranging from $0.62 \div 19.40 \mu \mathrm{g} / \mathrm{m}^{3}$.

In order to assess the risk of developing leukemia as a result of exposure to benzene at a specified measured or imagined concentration in the air we have to calculate, from the recorded concentrations found in the air of the operating room, a hypothetic life span exposure. Let us assume, hypothetically, the worst possible scenario of exposure, for example $7 \mathrm{~h}$ of working at the operating table, 7 days a week over a period of 30 years, receiving a range of concentrations, so called "lifetime medium."

$$
\begin{aligned}
& 0.62 \times \frac{7}{24} \times \frac{5}{7} \times \frac{30}{70}=0.055 \mu \mathrm{g} / \mathrm{m}^{3} \\
& 19.40 \times \frac{7}{24} \times \frac{5}{7} \times \frac{30}{70}=1.732 \mu \mathrm{g} / \mathrm{m}^{3}
\end{aligned}
$$

And so a concentration of $0.62 \mathrm{pg} / \mathrm{m}^{3}$ corresponds to an additional risk of leukemia ranging from $1.21 \times 10^{-10} \div 4.29 \times 10^{-10}$, but a concentration of $19.40 \mathrm{pg} / \mathrm{m}^{3}$ corresponds to an additional risk of leukemia at $4.27 \times 10^{-8} \div 1.51 \times 10^{-7}$.
The data for toluene, ethylbenzene and xylene is not adequate enough to assess their human carcinogenic potential and it is impossible to quantitatively calculate the carcinogenic potential from inhalation exposure.

In the case of dioxins and dioxin-like compounds, the situation is more complicated since a consensus as to the carcinogenicity of dioxins to humans has not been achieved. For example Cole et al. [7] states: "It is clear from this review that the evidence does not support the IARC's classification of TCDD as a group 1 carcinogen. In fact, the evidence indicates that TCDD is not carcinogenic to human beings at low levels and that it may not be carcinogenic to them even at high levels." Yet most other researchers believe that dioxins are not carcinogenic to humans [8]. Documents prepared by the US Environmental Protection Agency (U.S. EPA) up till 2010 are accompanied by a clause." Also in the latest materials [9] there is no information concerning the carcinogenic effect of tetrachlorodibenzo-p-dioxin (TCDD) to humans, in situations of digestive and inhalation exposure.

In order to present the reader with at least a trace of information on the risk of developing cancer due to the exposure to dioxins, we will use the linear model presented by the EPA study (2007) for 2,3,7,8-TCDD. The estimated unit risk in conditions of inhalation exposure is equal to $3.3 \times 10^{-5}\left(\mathrm{pg} / \mathrm{m}^{3}\right)^{-1}$. Human lung cancer, soft-tissue sarcomas, lymphomas, stomach carcinomas are mentioned as results of exposure to 2,3,7,8-TCDD [10-12].

Individual risk was defined as the additional risk of developing cancer as the result of human lifelong exposure to a unit of concentration of the tested substance in the inhaled air. In this case, the unit of concentration was set at $1 \mathrm{pg} / \mathrm{m}^{3}$.

In order to estimate the risk of cancer associated with the exposure to the studied substance, we must convert the concentration measured at the workplace to the average concentration over a lifespan. We assume, as in the case of benzene the worst possible scenario, i.e., $7 \mathrm{~h}$ 
of work at the operating table, 7 days a week for a period of 30 years.

The average concentration of 2,3,7,8-TCDD measured in the operating room was $0.13 \mathrm{pg} / \mathrm{m}^{3}$, which, when converted to the lifespan concentration, was $0.0116 \mathrm{pg} / \mathrm{m}^{3}$ and corresponding exposure risk of $3.83 \times 10^{-7}$ :

$$
0.13 \times \frac{7}{24} \times \frac{5}{7} \times \frac{30}{70}=0.0116 \mathrm{pg} / \mathrm{m}^{3}
$$

Recommended toxicity equivalence factors (TEFs) for human health risk assessment of polychlorinated dibenzop-dioxins, dibenzofurans, and dioxin-like polychlorinated biphenyls were developed for dioxins and furans $[13,14]$ ). These factors allow you to calculate the equivalent concentration compared to a mixture of 2,3,7,8-TCDD. Taking into account all "dioxin-like" compounds found in the operating room, we obtained a concentration of $0.19 \mathrm{pg} / \mathrm{m}^{3}$. The resultant lifespan concentration is $0.017 \mathrm{pg} / \mathrm{m}^{3}$ which corresponds to the risk of $5.61 \times 10^{-7}$. Comparing average concentrations and corresponding risks of 2,3,7,8TCDD alone to the mixture, suggests that, when assessing the risk, the impact of the other components, like dioxins and furans, can be neglected without much impairment. The discussions about the dangers of chemicals contained in the smoke evolving during laparoscopic surgery have already been undertaken in 1996, by organizations such as Association of Registered Nurses (AORN), Occupational Safety and Health Administration (OSHA), National Institute for Occupational Safety and Health (NIOSH), and Emergency Care Research Institute (ECRI) [15]. Despite the low concentrations of these chemical compounds, these organizations see a need to evacuate smoke from the operating room.

\section{CONCLUSIONS}

During the rapid development of laparoscopic and robotic surgical procedures, the discussed problem is important for a large number of medical staff.
After assessing the risk of cancer associated with exposure to benzene, dioxins and other compounds found in the atmosphere of the operating room, it can be concluded that their concentrations are so small that they do not offer a real risk to exposed workers.

We are convinced that, despite the low concentrations of the test compounds, the problem can not be ignored. Further research in this area should be carried out. It is important to use all available options to protect personnel in the operating room from exposure to toxic chemicals.

\section{REFERENCES}

1. Brüske-Hohlfeld I, Preissler G, Jauch K-W, Pitz M, Nowak D, Peters A, Wichmann H. Surgical smoke and ultrafine particles. J Occup Med Toxicol. 2008;3:31, http://dx.doi.org/ 10.1186/1745-6673-3-31.

2. Barrett WL, Garber SM. Surgical smoke: A review of the literature. Is this just a lot of hot air? Surg Endosc. 2003;17(6): 979-87, http://dx.doi.org/10.1007/s00464-002-8584-5.

3. Dobrogowski M, Wesołowski W, Kucharska M, Sapota A, Pomorski L. Chemical composition of surgical smoke formed in the abdominal cavity during laparoscopic cholecystectomy - Assessment of the risk to the patient. Int J Occup Med Environ Health. 2014;27(2):1-12, http://dx.doi.org/10.2478/ s13382-014-0250-3.

4. Mihashi S, Ueda S, Hirano M, Tomita Y, Hirohata T. Some problems about condensates induced by $\mathrm{CO}_{2}$ laser irradiation. In: Proceedings of the 4th Congress of the International Society for Laser Surgery, 1981 Feb 21-24; Tokyo, Japan. Tokyo: Japan Society for Laser Medicine; 1981:2.25-22.27.

5. Ott DE. Smoke and particulate hazards during laparoscopy procedures. Surg Serv Manag. 1997;3:11-3.

6. Environmental Protection Agency. Carcinogenic effects of benzene: An update. Washington: National Center for Environmental Health, Office of Research and Development; 1998.

7. Cole P, Trichopoulos D, Pastides H, Starr T, Mandel JS. Dioxin and cancer: A critical review. Regul Toxicol Pharmacol. 2003;38:378-88, http://dx.doi.org/10.1016/j.yrtph.2003.08.002. 
8. Crump KS, Canady R, Kogevinas M. Meta-analysis of dioxin cancer dose response for three occupational cohorts. Environ Health Perspect. 2003;111(5):681-7, http://dx.doi. org/10.1289/ehp.5831.

9. Integrated Risk Information System. 2,3,7,8-Tetrachlorodibenzo-p-dioxin (TCDD); CASRN 1746-01-6. Washington: The System; 2012.

10. Environmental Protection Agency. Health Effects Assessment Summary Tables. FY 1997 Update. Washington: The Agency; 1997.

11. Environmental Protection Agency. 2,3,7,8-Tetrachlorodibenzo-p-dioxin (2,3,7,8-TCDD). Hazard summary created in April 1992; Revised in January 2000 [cited 2014 Jun 15]. Technology Transfer Network. Available from: http:/www.epa.gov/ttnatw01/hithef/ dioxin.html.
12. Steenland K, Deddens J. Dioxin: Exposure-response analyses and risk assessment. Ind Health. 2003;41:175-80, http:// dx.doi.org/10.2486/indhealth.41.175.

13. Environmental Protection Agency (EPA). EPA's reanalysis of key issues related to dioxin toxicity and response to NAS comments. Cincinnati $(\mathrm{OH})$ : National Center for Environmental Assessment Office of Research and Development U.S. Environmental Protection Agency; 2010.

14. Environmental Protection Agency. Recommended toxicity equivalence factors (TEFs) for human health risk assessments of 2,3,7,8-tetrachlorodibenzo-p-dioxin and dioxinlike compounds. Washington: Risk Assessment Forum U.S. Environmental Protection Agency; 2010.

15. Giordano BP. Don't be a victim of surgical smoke. AORN J. 1996;63(3):520-2, http://dx.doi.org/10.1016/S0001-2092(06) 63389-9.

This work is available in Open Access model and licensed under a Creative Commons Attribution-NonCommercial 3.0 Poland License - http://creativecommons.org/ licenses/by-nc/3.0/pl/deed.en. 